\title{
A Multicenter Study of Prevalence and Risk Factors for Allergic Rhinitis in Primary School Children in 5 Cities of Hubei Province, China
}

\author{
Xiaoting Tong ${ }^{a, b} \quad H_{u a n} T_{0}{ }^{a, b} \quad$ Ling Gao $^{a} \quad$ Yuqin Deng $^{a}$ Rong Xiang ${ }^{a}$ \\ Ruixiang Cen ${ }^{c}$ Yan Zhao $^{d}$ Pengju Wange ${ }^{e}$ Guo Li $^{f}$ Jingqiu Shen ${ }^{g}$ \\ Bisheng $\mathrm{Xu}^{\mathrm{h}}$ Benchao He ${ }^{\mathrm{h}}$ Yonggang Kong ${ }^{\mathrm{a}}$ Zezhang Tao ${ }^{\mathrm{a}, \mathrm{b}} \mathrm{Yu} \mathrm{Xu}^{\mathrm{a}, \mathrm{b}}$ \\ Hubei Medical Quality Control Center for Allergic Disease

\begin{abstract}
aDepartment of Otolaryngology - Head and Neck Surgery, Renmin Hospital of Wuhan University, Wuhan, China; ${ }^{b}$ Research Institute of Otolaryngology - Head and Neck Surgery, Renmin Hospital of Wuhan University, Wuhan, China; 'Huangshi Center Hospital, Affiliated Hospital of Hubei Polytechnic University, Edong Healthcare Group, Huangshi, China; dJingmen No. 1 People's Hospital, Jingmen, China; 'Xiangyang Center Hospital, Xiangyang, China; 'Zaoyang No. 1 Renmin's Hospital, Xiangyang, China; 9The first Hospital of Laohekou,

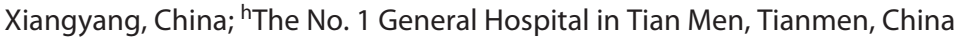

\section{Keywords}

Allergic rhinitis · Children · Epidemiology · Prevalence · Risk factors

\begin{abstract}
Background: Few data are available concerning the prevalence and risk factors for allergic rhinitis (AR) in school children in Hubei Province which is located in the central part of China. This study investigated the epidemiological features of AR among school children in Hubei Province. Methods: A cross-sectional questionnaire survey on AR in school children was carried out in 5 cities in Hubei Province by cluster sampling from June to September 2018. Questionnaires were filled out by children and their parents jointly. The diagnostic criteria of AR were according to the SFAR. Questions from the questionnaire were used to examine the pattern of AR. Logistic regression analysis was used to assess the risk factors for childhood allergies. Results: The total prevalence rate of AR was $16.16 \%$, with $24.31 \%$ (Wuhan), $4.34 \%$
\end{abstract}

karger@karger.com www.karger.com/iaa

Karger $\stackrel{\text { ' }}{5}$

BOPEN ACCESS
(C) 2021 The Author(s)

Published by S. Karger AG, Basel

This is an Open Access article licensed under the Creative Commons Attribution-NonCommercial-4.0 International License (CC BY-NC) (http://www.karger.com/Services/OpenAccessLicense), applicable to the online version of the article only. Usage and distribution for commercial purposes requires written permission.
(Xiangyang), 4.31\% (Tianmen), 10.92\% (Jingmen), and $11.42 \%$ (Huangshi), respectively. The prevalence of AR was positively correlated with gross domestic product per capita $(p<0.05)$. Multivariate analysis revealed that male, city of Wuhan, family history of allergy, food allergy, drug allergy, air purifier, exposure to dust, living in towns or urban area before 2 years old, maternal age for 26-35 years old, and frequent application of antibiotics increased the risk of $A R$, while daily outdoor time for $1-2 \mathrm{~h}$, daily sleeping time $>8 \mathrm{~h}$, siblings, and breastfeeding for $>6$ months reduced the risk significantly. Conclusion: We found the apparent geographic variation of children allergies in Hubei Province. Both genetic and environment factors had impacts on the prevalence of AR in school children. Public policies should specifically target at the local risk factors for different areas.

(C) 2021 The Author(s)

Published by S. Karger AG, Basel

Xiaoting Tong and Huan Tong contributed equally to the study. Edited by H.-U. Simon, Bern.
Correspondence to:

Zezhang Tao, taozezhang@163.com

YuXu,xuy@whu.edu.cn 


\section{Introduction}

Allergic rhinitis (AR) is a symptomatic disorder when inhaled particles contact the nasal mucosa and induce an immunoglobulin E-mediated inflammatory response, which is characterized by sneezing, nasal obstruction, and mucous discharge [1]. Epidemiological studies have revealed that the prevalence of AR has increased progressively in more developed countries over the past few years and currently affects $10-40 \%$ of adults and $2-25 \%$ of children worldwide [2-4]. In recent decades, a rising trend of AR in China has been observed, with a widely varying prevalence particularly $[5,6]$. The trend of AR incidence has become a significant economic burden on the general public [7].

AR has been proved to be an important risk factor that will cause many disorders, especially in children. It has been verified that AR exerted significant effects on students' social performance, emotion, memory, sleep quality, and psychosocial interactions $[8,9]$. To date, the only one nationwide survey of the prevalence of AR in children in China demonstrated that the mean prevalence in 8 metropolitan cities of provinces in 4 regions was $9.8 \%$ [10]. There are few studies on the prevalence of AR in Hubei Province, which is located in the central part of China and one of the important economic trading centers in China. Because of the different geographical locations of the cities in Hubei Province, the environment and development status of each city is dramatically different. Different levels of economic development and urbanization among cities in Hubei Province over the past years also changed the lifestyle features of inhabitants. The aim of the present study was to determine the recent prevalence rates and risk factors of AR in children from 5 major cities in Hubei Province in China, to provide baseline information for clinicians and health policymakers.

\section{Materials and Methods}

\section{Study Design}

A cross-sectional survey was undertaken among children aged 6-12 years in 5 cities of Hubei Province from June 2018 to September 2018, using a cluster-stratified sampling method. The 5 cities included Wuhan, Xiangyang, Jingmen, Huangshi, and Tianmen, which were major cities in Hubei Province with different economic levels. Xiangyang is situated in the northwest part of Hubei Province, Tianmen and Jingmen in central Hubei Province, Wuhan in east Hubei Province, and Huangshi is located in southeast Hubei Province. They were located from north to south throughout $\mathrm{Hu}$ bei Province. Therefore, the survey results are geographically and economically representative to some extent.

The target sample size equaled 544 per city which was calculated referring to the survey of Zhang et al. [11]. The calculating formula was $N=Z^{2} P(1-P) / d^{2}$, where $N$ is the sample size, $Z$ is the statistic for a level of confidence (equal to 1.96 for the level of confidence of $95 \%), P$ is the estimated prevalence of AR and is equal to 0.15 based on previous epidemiological surveys, and $d$ is precision, here chosen to be 0.03 . However, considering nonresponse bias, the sample size was set to at least 800 per city. In each city, 2 urban districts were randomly selected, and 1-3 primary schools were chosen at random in each selected district. A total of 10,757 children were randomly selected, of whom 5,553 were from $\mathrm{Wu}$ han, 1,981 from Xiangyang, 859 from Tianmen, 980 from Jingmen, and 1,384 from Huangshi. The study was approved by the Ethics Review Committee of Renmin Hospital of Wuhan University (2017K-C047).

Table 1. Self-completed questionnaire, attributed score, and repartition of the items for the SFAR

\begin{tabular}{llc}
\hline Item discriminators & Score (points) & $\begin{array}{l}\text { Cumulative } \\
\text { score }\end{array}$ \\
\hline Nasal symptoms (blocked, runny nose, and/or sneezing) in the past year ${ }^{\mathrm{a}}$ & $\begin{array}{l}1 \text { for each symptom } \\
1 \text { for perennial } \\
\text { Months of the year }\end{array}$ & 3 \\
& 2 for pollen season & 5 \\
Nasal symptoms plus itchy eyes (rhinoconjunctivitis) & 2 & 7 \\
Triggers & & 9 \\
$\quad$ Pollens, house dust mites, dust & 2 & 11 \\
$\quad$ Epithelia (cat, dog) & 1 & 13 \\
Perceived allergic status & 2 & 14 \\
Previous positive allergic tests & 2 & 16 \\
Previous medical diagnosis of allergy & 1 & 16 \\
Familial history of allergy & 2 & \\
Total points & & \\
\hline
\end{tabular}

SFAR, Score for Allergic Rhinitis. ${ }^{a}$ At least one symptom. ${ }^{b}$ At least one trigger.

Prevalence and Risk Factors of Allergic Rhinitis
Int Arch Allergy Immunol 2022;183:34-44 DOI: $10.1159 / 000517948$ 


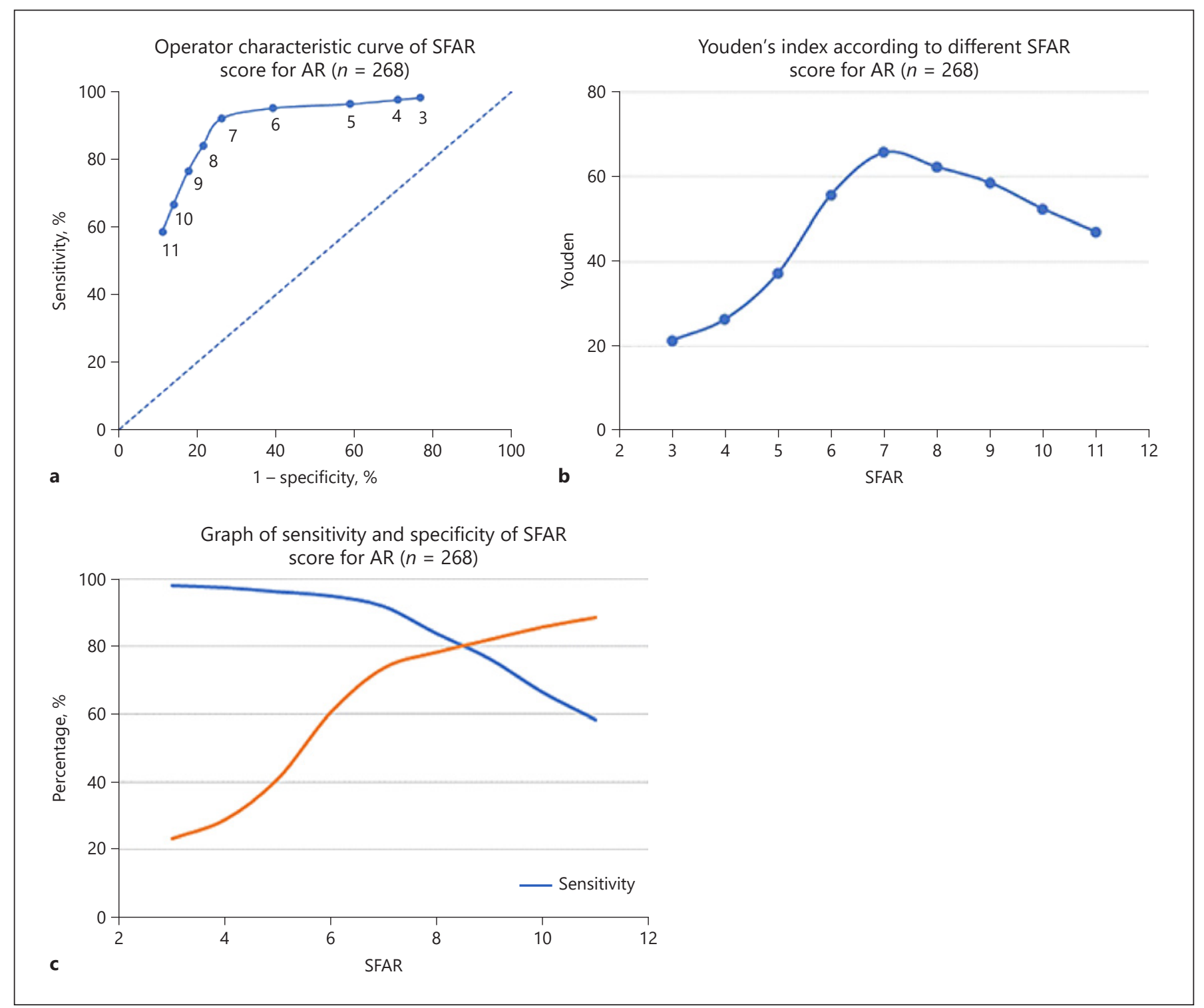

Fig. 1. The SFAR cutoff value. Operator characteristic curve of SFAR for AR $(n=268)$ (a); Youden's index according to different SFAR for AR $(n=268)(\mathbf{b})$; graph of sensitivity and specificity of SFAR for AR $(n=268)(\mathbf{c})$. SFAR, Score for Allergic Rhinitis; AR, allergic rhinitis.

\section{Questionnaires}

The questionnaire was designed by the authors with reference to the International Study of Asthma and Allergies in Childhood (ISAAC) [12], the European Community Respiratory Health Survey (ECRHS) [13], and Score for Allergic Rhinitis (SFAR) [14], including questions regarding nasal symptoms, duration and severity, self-reported allergens, and concomitant and family history of allergic disease as well as related factors. The questionnaire was distributed in the form of 2-dimensional code and filled out by children and their parents jointly through the Wechat online system. The confirmed data were collected and imported into a form for further analysis.

\section{Working Definitions}

The diagnostic criteria of AR were according to the SFAR (shown in Table 1). The SFAR was calculated by summing the score obtained under the different items of the questionnaire. To ensure credibility and accuracy, 268 participants from Hubei Province were included in the diagnosis validation of SFAR, and their result of serum-specific IgE was used to assess the SFAR cutoff value. On the basis of the receiver operator characteristic curve (shown in Fig. 1a) and the Youden's index (shown in Fig. 1b), the best cutoff value was set at $\geq 7$, which allowed the SFAR to be adequately sensitive (91.9\%) and specific (73.8\%) (shown in Fig. 1c). So, an SFAR $\geq 7$ is adopted to define the presence of AR in our study. Self-report was used to diagnose the allergic comorbidity and infective diseases. 
Table 2. Distribution of age and gender in AR children: $n$ (\%)

\begin{tabular}{|c|c|c|c|c|c|c|}
\hline Male & 835 (27.87) & $104(13.42)$ & $48(4.66)$ & $71(13.65)$ & $26(5.33)$ & $1,084(18.66)$ \\
\hline Female & $515(20.14)$ & $54(8.87)$ & $38(4.00)$ & $36(7.83)$ & $11(2.96)$ & $654(13.22)$ \\
\hline$\chi^{2}$ & 44.795 & 6.998 & 0.526 & 8.523 & 2.855 & 58.442 \\
\hline 6 & $111(29.29)$ & $2(6.90)$ & $2(12.50)$ & $9(7.83)$ & $1(5.26)$ & $125(22.40)$ \\
\hline 7 & $268(25.12)$ & $30(11.72)$ & $9(3.69)$ & $31(12.86)$ & $1(1.45)$ & $339(18.06)$ \\
\hline 8 & $270(27.49)$ & $30(11.36)$ & $13(3.69)$ & $19(12.93)$ & $4(4.08)$ & $336(18.23)$ \\
\hline 9 & $199(22.54)$ & $27(10.47)$ & $11(3.30)$ & $9(7.63)$ & $7(5.19)$ & $253(14.65)$ \\
\hline 10 & $269(21.73)$ & $21(8.50)$ & $19(3.83)$ & $14(11.38)$ & $10(5.65)$ & $333(14.60)$ \\
\hline 11 & $106(25.54)$ & 25 (13.59) & $12(5.29)$ & $12(11.65)$ & $5(2.78)$ & $160(14.43)$ \\
\hline Total & $1,350(24.31)$ & $158(11.42)$ & $86(4.34)$ & 107 (10.92) & $37(4.31)$ & $1,738(16.16)$ \\
\hline
\end{tabular}

AR, allergic rhinitis.

Collecting Data for Population and Socioeconomic Status

To assess the association between the standardized prevalence of AR and population or socioeconomic status in 2018, we obtained the data from the National Bureau of Statistics of China (http://www.stats.gov.cn).

\section{Statistical Analysis}

Data were computer-entered by 2 researchers (double data entry greatly reduces errors). SPSS statistical software (version 23.0) was used for analysis. Measurements are given as means with standard deviations; count data are shown as rates or ratios. Percentage or mean \pm SD was used to describe categorical and continuous variables, respectively. The $t$ test and $\chi^{2}$ test or Fisher's exact test were used to analyze the differences between subgroups. Multivariate logistic regression was performed, a stepwise regression model, to assess the relationship of AR with the potential risk factors. Subjects with missing values were excluded from the regression model. $p<0.05$ was considered statistically significant.

\section{Results}

\section{Subject Characteristics and Prevalence of $A R$}

In total, 10,757 valid questionnaires were returned from the primary school children and their parents (Wuhan 5,553, Xiangyang 1,981, Tianmen 859, Jingmen 98, and Huangshi 1,384). The mean age of the sample was 9.12 years $(\mathrm{SD}=1.76)$, with 5,809 male students (54.0\%) and 4,948 female students (46.0\%). Among the respondents, 1,738 (16.16\%) diagnosed AR totally. The prevalence rate of AR was $24.31 \%$ (Wuhan), $4.34 \%$ (Xiangyang), 4.31\% (Tianmen), 10.92\% (Jingmen), and $11.42 \%$ (Huangshi), respectively. The incidence of AR in Wuhan is significantly higher than other cities $(p<0.05)$ and that in Xiangyang and Tianmen was significantly lower than other cities $(p<0.05)$. In addition, there was no statistical difference between Xiangyang and Tianmen, as well as between Jingmen and Huangshi. The overall percentage of male patients was larger than the female patients ( 18.66 vs. $13.22 \%$; $p<0.05)$. The distribution of age and gender in all AR children in 5 cities is shown in Table 2.

\section{Self-Reported Symptoms and Allergens}

Of the 1,738 who were diagnosed with AR, nasal blockage was the most common complaint, with an incidence of $92.23 \%(1,603)$. One thousand five hundred twenty $(87.46 \%)$ children complained about sneezing, 1,517 $(87.28 \%)$ were troubled by nasal itching, and 1,381 (79.46\%) had running nose. Each nasal symptom had similar degree of effects on daily activities $(p>0.05)$. The number of AR patients who showed itching eye and bronchial symptoms was $1,135(65.30 \%)$ and 1,295 (74.51\%), respectively. Cough (70.48\%) was found to be the most common bronchial symptom and more serious than chest tightness, wheezing, and dyspnea. 
Table 3. Triggers of nasal symptoms in AR patients

\begin{tabular}{|c|c|c|c|c|c|c|c|}
\hline Cities & $\begin{array}{l}\text { Dust mites or } \\
\text { dust }\end{array}$ & $\begin{array}{l}\text { Temperature } \\
\text { change }\end{array}$ & Cold air & Pollens & $\begin{array}{l}\text { Animal } \\
\text { dander }\end{array}$ & Soot & Others \\
\hline Wuhan & $1,248(92.4)$ & $940(69.6)$ & $870(64.4)$ & $650(48.1)$ & $361(26.7)$ & $192(14.2)$ & $110(8.1)$ \\
\hline Xiangyang & $65(75.6)$ & $50(58.1)$ & $54(62.8)$ & $49(57.0)$ & $19(22.1)$ & $10(11.6)$ & $5(5.8)$ \\
\hline Jingmen & $93(86.9)$ & $76(71.0)$ & $71(66.4)$ & $54(50.5)$ & $42(39.3)$ & $25(23.4)$ & $7(6.5)$ \\
\hline Tianmen & $30(81.1)$ & $20(54.1)$ & $18(48.6)$ & $17(45.9)$ & $10(27.0)$ & $8(21.6)$ & $2(5.4)$ \\
\hline
\end{tabular}

AR, allergic rhinitis.

Fig. 2. Season features.
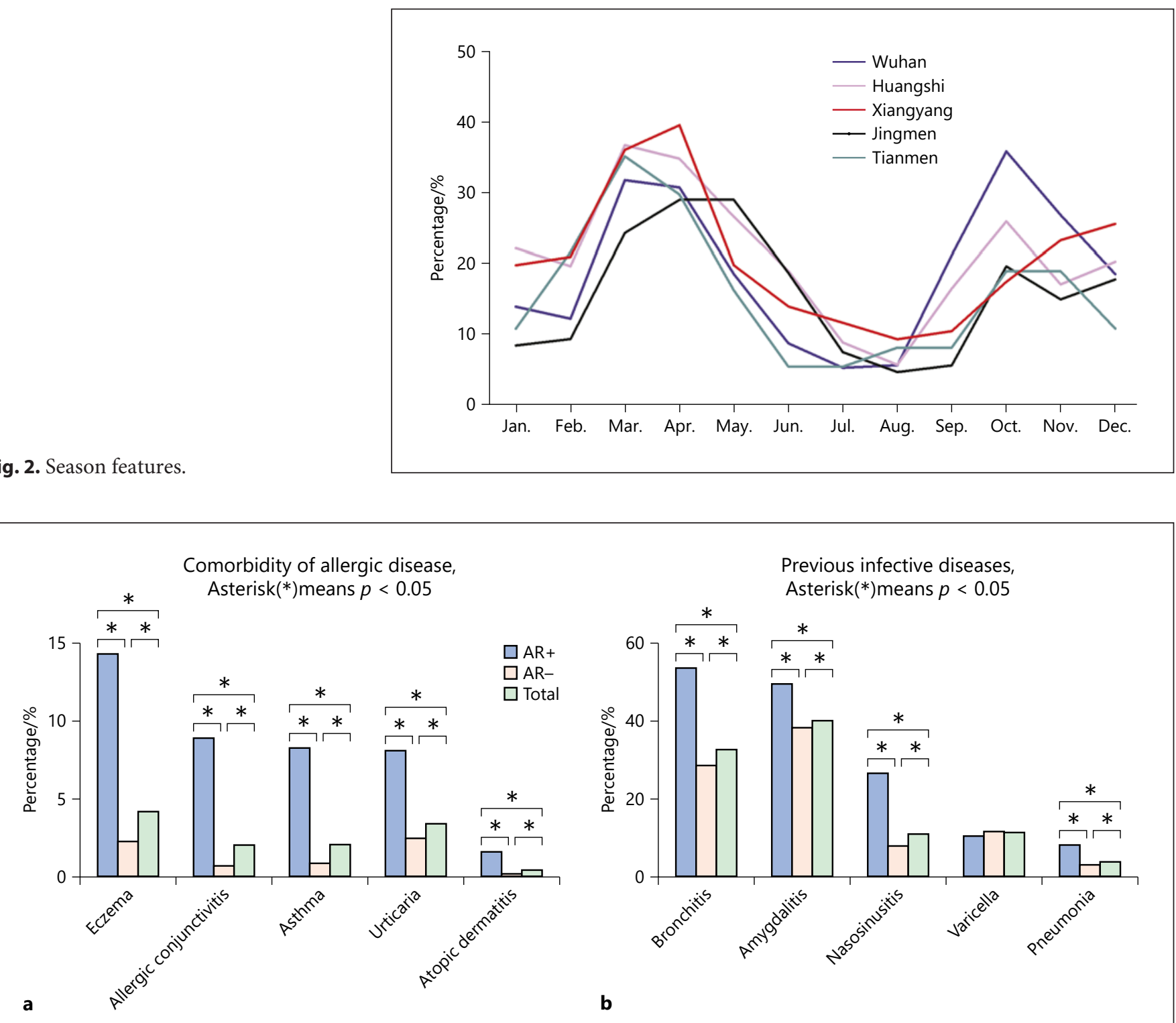

Fig. 3. Self-reported comorbidities. Comorbidity of allergic disease, ${ }^{*} p<0.05$ (a); previous infective diseases, ${ }^{*} p<0.05$ (b). 
Table 4. Economic and population data from the 5 cities in Hubei Province (2018)

\begin{tabular}{lrrr}
\hline City & $\begin{array}{l}\text { GDP, } \\
\text { billion CNY }\end{array}$ & $\begin{array}{l}\text { Population, } \\
\text { thousands }\end{array}$ & $\begin{array}{l}\text { GDP per capita, } \\
\text { CNY/person }\end{array}$ \\
\hline Wuhan & $1,484.73$ & $11,081.0$ & $133,988.72$ \\
Huangshi & 158.73 & $2,470.7$ & $64,246.17$ \\
Jingmen & 184.79 & $2,896.5$ & $63,797.34$ \\
Tianmen & 59.12 & $1,272.3$ & $46,463.10$ \\
Xiangyang & 430.98 & $5,669.0$ & $76,023.81$ \\
\hline$r$ & 0.856 & 0.785 & 0.880 \\
\hline$p$ value & 0.064 & 0.116 & 0.049 \\
\hline
\end{tabular}

GDP, gross domestic product; CNY, Chinese yuan renminbi.

Season features and triggers of nasal symptoms are shown in Figure 2 and Table 3. Dust mites or dust was the most common factor triggering nasal symptoms compared to temperature change, cold air, pollen, pet, soot, and others. Moreover, 56.67\% patients showed seasonal onset. Season incidence had 2 peaks: one in spring (March 32.05\% and April 31.42\%) and one in autumn (October 32.68\%). We combined the data of each city of AR because the tendency between 5 cities was similar.

\section{Self-Reported Comorbidities}

Other allergic diseases combined with AR include eczema (14.27\%), allergic conjunctivitis (8.92\%), asthma $(8.29 \%)$, urticaria $(8.11 \%)$, and atopic dermatitis (1.61\%). Eczema was the most common one of these. The incidence of all combined allergic diseases was higher in the AR-positive group than in the AR-negative group, showing a statistical meaning ( $p<0.05$; shown in Fig. 3a). The previous infective disease of all participants is shown in Figure 3 b, covering bronchitis, amygdalitis, nasosinusitis, varicella, and pneumonia. The incidence of all infective diseases in the AR-positive group was significantly higher than that in the AR-negative group, except varicella $(p<0.05)$.

\section{The Influences of Population Size and Socioeconomic \\ Status}

The prevalence of AR was positively correlated with gross domestic product (GDP) per capita $(r=0.8796, p<$ $0.05)$. But, there was no correlation with the size of the population of the cities $(p>0.05)$, neither the GDP of each city $(p>0.05)$, as shown in Table 4 .

Prevalence and Risk Factors of Allergic Rhinitis

\section{Potential Risk Factors}

The univariate analysis and the multivariate analysis revealing potential risk factors associated with AR are shown in Tables 5 and 6, respectively. We found male, city of Wuhan, family history of allergy, food allergy, drug allergy, air purifier, exposure to dust, living in towns or urban area before 2 years old, maternal age for 26-35 years old, and frequent application of antibiotics increased the risk of AR, while daily outdoor time for 1-2 $\mathrm{h}$, daily sleeping time $>8 \mathrm{~h}$, siblings, and breastfeeding for $>6$ months reduced the risk significantly.

\section{Discussion}

$\mathrm{AR}$ is a major burden on affected children and their families and is becoming a serious challenge to public health organization and healthcare providers. In the last 2 decades, the prevalence of AR in China dramatically increased $[5,15]$. Several time trend research studies in European and Asian countries showed that the incidence of AR in primary school children is on the rise [16-19]. In the context of the global trend of increasing prevalence of AR, the overall epidemiological data on primary school children in Hubei Province are scarce. Hubei Province is situated in the middle part of China and spans $4^{\circ}$ of latitude (from $29^{\circ} 01^{\prime} \mathrm{N}$ to $33^{\circ} 6^{\prime} \mathrm{N}$ ) and over $8^{\circ}$ of longitude (from $108^{\circ} 21^{\prime} \mathrm{E}$ to $116^{\circ} 07^{\prime} \mathrm{E}$ ) with the population of $>59$ million. It has an area of around 185,900 square kilometers and is traditionally divided into 13 prefectural-level divisions. Besides, the regional large span could lead to unbalanced incidence of atopic illness. Therefore, in order to investigate the prevalence of AR in Hubei Province and its association with factors such as locations, socioeconomic status, and self-reported allergens and so on, our survey explored the prevalence of children aged 6-12 years in 6 major cities in Hubei Province by combining a questionnaire with SFAR.

In contrast to the methods previously used for epidemiological research including postal questionnaire surveys, face-to-face interviews, and telephone interviews, our online questionnaire survey reduced the waste of time and money and was more convenient to be collected and arranged. In our study, diagnosis validation of SFAR was described in detail above, making it applicable to this survey in large sample capacity and areas far away from the laboratory.

The overall prevalence of 5 cities of Hubei Province in our study was $16.16 \%$ (Wuhan $24.31 \%$, Xiangyang $4.13 \%$, Tianmen 4.31\%, Jingmen $10.92 \%$, and Huangshi 11.42\%).

Int Arch Allergy Immunol 2022;183:34-44 DOI: $10.1159 / 000517948$ 
Table 5. Potential risk factors associated with AR

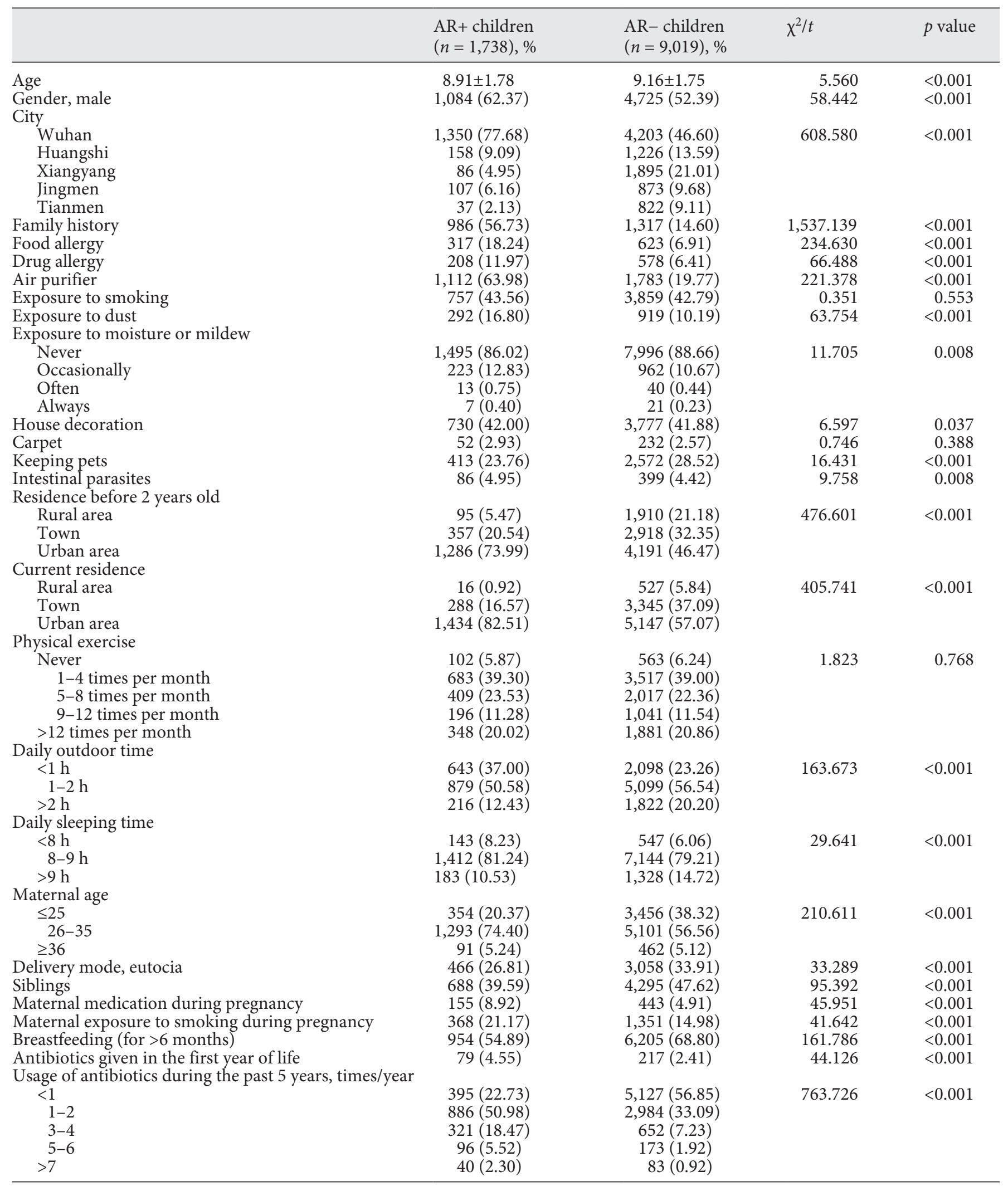

AR, allergic rhinitis. 
Table 6. The ORs and 95\% CI of risk factors associated with AR

\begin{tabular}{|c|c|c|c|c|}
\hline & \multirow[t]{2}{*}{ OR } & \multicolumn{2}{|l|}{$95 \%$ CI } & \multirow[t]{2}{*}{$p$ value } \\
\hline & & lower & upper & \\
\hline Gender, male & 1.608 & 1.426 & 1.814 & $<0.001$ \\
\hline \multicolumn{5}{|l|}{ City } \\
\hline Wuhan & 1 & & & \\
\hline Huangshi & 0.719 & 0.581 & 0.890 & 0.002 \\
\hline Xiangyang & 0.305 & 0.233 & 0.399 & $<0.001$ \\
\hline Jingmen & 0.699 & 0.544 & 0.899 & 0.005 \\
\hline Tianmen & 0.330 & 0.226 & 0.483 & $<0.001$ \\
\hline Family history & 4.732 & 4.192 & 5.341 & $<0.001$ \\
\hline Food allergy & 1.899 & 1.597 & 2.258 & $<0.001$ \\
\hline Drug allergy & 1.265 & 1.038 & 1.542 & 0.020 \\
\hline Air purifier & 1.394 & 1.223 & 1.589 & $<0.001$ \\
\hline Exposure to dust & 2.294 & 1.932 & 2.723 & $<0.001$ \\
\hline \multicolumn{5}{|l|}{ Residence before 2 years old } \\
\hline Rural area & 1 & & & \\
\hline Town & 2.047 & 1.583 & 2.648 & $<0.001$ \\
\hline Urban area & 2.196 & 1.702 & 2.832 & $<0.001$ \\
\hline \multicolumn{5}{|l|}{ Daily outdoor time } \\
\hline$<1 \mathrm{~h}$ & 1 & & & \\
\hline $1-2 \mathrm{~h}$ & 0.848 & 0.743 & 0.968 & 0.015 \\
\hline$>2 \mathrm{~h}$ & 0.864 & 0.712 & 1.049 & 0.140 \\
\hline \multicolumn{5}{|l|}{ Daily sleeping time } \\
\hline$<8 \mathrm{~h}$ & 1 & & & \\
\hline $8-9 \mathrm{~h}$ & 0.752 & 0.603 & 0.939 & 0.012 \\
\hline$>9 \mathrm{~h}$ & 0.736 & 0.558 & 0.970 & 0.029 \\
\hline \multicolumn{5}{|l|}{ Maternal age } \\
\hline$\leq 25$ & 1 & & & \\
\hline $26-35$ & 1.208 & 1.040 & 1.403 & 0.013 \\
\hline$\geq 36$ & 1.217 & 0.910 & 1.628 & 0.185 \\
\hline Siblings & 0.878 & 0.776 & 0.994 & 0.040 \\
\hline Breastfeeding (for $>6$ months) & 0.767 & 0.678 & 0.868 & $<0.001$ \\
\hline Antibiotics given in the first year of life & 1.632 & 1.196 & 2.226 & 0.002 \\
\hline \multicolumn{5}{|c|}{ Usage of antibiotics during the past 5 years, times/year } \\
\hline$<1$ & 1 & & & \\
\hline $1-2$ & 1.757 & 1.510 & 2.046 & $<0.001$ \\
\hline $3-4$ & 2.568 & 2.110 & 3.125 & $<0.001$ \\
\hline $5-6$ & 3.397 & 2.497 & 4.622 & $<0.001$ \\
\hline$>7$ & 2.501 & 1.583 & 3.953 & $<0.001$ \\
\hline
\end{tabular}

AR, allergic rhinitis.

Our survey showed a geographic variation in the prevalence of AR across different regions of Hubei Province, and the prevalence rates of AR are higher in more developed areas than developing areas. Multivariate logistic regression revealed that the standardized prevalence of AR was positively correlated with GDP per capita. Wuhan, the capital of Hubei Province, is more developed than the other 4 cities and has the highest incidence of AR. In contrast to the surveys from developed countries that higher socioeconomic status predicted lower prevalence of allergies [2022], the present study suggested that higher individual-level socioeconomic status predicted higher prevalence of $A R$ which was consistent with previous studies in China [10].
These may be probably a consequence of the rapid development of industries and living standard, which resulted in changes in environment factors. There are accumulating pieces of evidence that environmental factors play important roles in the etiology of AR. A study, which was conducted on the relationship between air pollution and AR in Taiwanese school children, demonstrated that the prevalence of AR was significantly associated with sulfur dioxide, carbon dioxide, and nitric oxides [23]. Compared with other cities, Xiangyang and Tianmen have a lower level of urbanization, which may result in a lower concentration of urban air pollution. This may explain why the prevalence of AR in Xiangyang and Tianmen was the lowest. 
Consistent with other surveys in several Chinese cities [24], we found that the incidence of nasal symptoms has a distinct seasonal variation, which showed 2 peaks in spring and autumn. Frequent and severe temperature changes are reported to be the most common cause of nasal symptoms during spring and autumn. Meanwhile, spring and autumn are often the peak seasons for pollen transmission. These factors may be responsible for the seasonal variation.

In our survey, we found that male, family history of allergy, food or drug allergy, air purifier, exposure to dust, living in towns or urban area before 2 years old, maternal age for 25-35 years old, and frequent application of antibiotics increased the risk of AR. The prevalence of AR in males was significantly higher than that in females, indicating a gender-based difference, in line with data from previous studies. It is probable that both hormonal changes with age and genetic susceptibility contribute to such difference [25]. As previous studies have shown, family history [26], food allergy, and drug allergy [27] are risk factors for AR in children, which is consistent with our findings. Air purifier is used to purify air and reduce the pollutants indoor. But, we found that using air purifiers was a risk factor for AR in children. We speculated the reason might be related to the emission of the exhaust gas from the air purifier, such as carbon dioxide and ozone.

In our study, living in towns or urban area before 2 years old increased the risk of AR, which could be attributed to different lifestyle and vehicle exhaust between urban areas and rural areas. Previous studies have found that exposure to traffic-related air pollution during early childhood or pregnancy could increase the incidence of AR in children $[28,29]$. On the other hand, a number of studies have shown that living on a farm at preschool age had a protective effect on allergies [30-32], suggesting that endotoxin exposure in childhood may influence the likelihood of developing AR. Several research studies indicated that antibiotics given was associated with AR [30]. We found that children taking antibiotics more than once a year were 3.39 times approximately more likely to develop AR than children taking antibiotics less than once a year. Therefore, it is important that doctors should avoid the overuse of antibiotics for reducing the risk of AR in children.

Our data demonstrated that daily outdoor time for 1-2 $\mathrm{h}$, daily sleeping time $>8 \mathrm{~h}$, siblings, and breastfeeding for $>6$ months could reduce the risk of AR in children, which is consistent with previous research studies [33-35] approximately. It could be speculated that moderate outdoor activities, plenty of time to sleep, and breastfeeding may be appropriate to prevent AR. Furthermore, interestingly, we found a higher rate of intestinal parasitic infections in AR than in healthy people by using univariate analysis, whereas the multivariate analysis revealed that intestinal parasitic infections did not affect the risk of AR $(p>0.05)$. Previous studies showed that the reduced exposure to parasites in a rural village of Bolivian Chaco associates with higher prevalence of grass pollen sensitization [36]. Recently, research has reported that infection with intestinal parasitic may selectively protect from pollen allergy because of the cross-react between them, which may behave as blocking antibodies and inhibiting allergic sensitization in susceptible individuals [37]. A Cuba study found that current intestinal parasitic infection protects against atopic dermatitis in children while past infections are risk factors for allergy [38]. Above all, the association between infections and allergy was apparently influenced by many underlying factors. The interactions differ depending on the type of intestinal parasitic and on the time of infestation. Therefore, further studies are needed to determine the relationship between infections and AR.

In conclusion, this is the first population-based random sample study that reported the prevalence of AR in primary school children in Hubei Province, which preliminarily looked into the characteristics of AR in this population. The study found strong evidence of the connection between social, behavioral, and biological factors and AR in primary school children in Hubei Province, indicating that strategies to reduce exposure to risk factors for childhood AR could be broadened. Presently, the study has limitations in that the sample size is small and only a limited number of risk factors were evaluated. AR is one of the most common diseases in young children in Hubei Province, which is higher in developed areas than in developing areas, suggesting an important role of lifestyle and environmental risk factors for AR in children. Public policies should specifically target at the local risk factors for different areas.

\section{Acknowledgments}

The authors thank all participants in this study for their enthusiastic cooperation during the data collection phase. They thank the Hubei Medical Quality Control Center for Allergic Disease for providing epidemiological expertise for the study.

\section{Statement of Ethics}

The Ethics Committee of Renmin Hospital of Wuhan University approved this study (2017K-C047). Written informed consent to participate in this study was obtained from all participants or their legal guardian before data collection.
Tong et al. 


\section{Conflict of Interest Statement}

The authors declared no potential conflicts of interest with respect to the research, authorship, and/or publication of this article.

\section{Funding Sources}

The authors disclose receipt of the following financial support for the research, authorship, and/or publication of this article: this study was supported by the National Natural Science Foundation of China (Nos. 81770986 and 82071017) and the Fundamental Research Funds for the Central Universities (No. 413000379).

\section{Author Contributions}

This study was designed by X.T. and H.T., who were the principal investigators. X.T. wrote the manuscript, and H.T. performed the statistical analysis. L.G., R.X., and Y.D. performed the clinical tests. Y.Z., P.W., G.L., J.S., B.X., B.H., and Y.K. were responsible for the supervision of data collection and advice on clinical diagnostic methods. Z.T. contributed to the analysis and interpretation of data for the study. Y.X. was responsible for advice on epidemiological methods, critical revisions of the manuscript for important intellectual content, and acquisition of funding for the study. All authors read and approved the final manuscript.

\section{References}

1 Bousquet J, Khaltaev N, Cruz AA, Denburg J, Fokkens WJ, Togias A, et al. Allergic rhinitis and its impact on asthma (ARIA) 2008 update (in collaboration with the World Health Organization, GA(2) LEN and AllerGen). Allergy. 2008;63(Suppl 86):8-160.

2 Bauchau V, Durham SR. Prevalence and rate of diagnosis of allergic rhinitis in Europe. Eur Respir J. 2004;24(5):758-64.

3 Asher MI, Montefort S, Björkstén B, Lai CK, Strachan DP, Weiland SK, et al. Worldwide time trends in the prevalence of symptoms of asthma, allergic rhinoconjunctivitis, and eczema in childhood: ISAAC phases one and three repeat multicountry cross-sectional surveys. Lancet. 2006;368(9537):733-43.

4 Meltzer EO, Blaiss MS, Naclerio RM, Stoloff SW, Derebery MJ, Nelson HS, et al. Burden of allergic rhinitis: allergies in America, Latin America, and Asia-Pacific adult surveys. Allergy Asthma Proc. 2012 Sep-Oct;33 Suppl 1: S113-41.

5 Zhang Y, Zhang L. Increasing prevalence of allergic rhinitis in China. Allergy Asthma Immunol Res. 2019;11(2):156-69.

6 Zhang Y, Zhang L. Prevalence of allergic rhinitis in china. Allergy Asthma Immunol Res. 2014;6(2):105-13.

7 Cheng L, Chen J, Fu Q, He S, Li H, Liu Z, et al. Chinese society of allergy guidelines for diagnosis and treatment of allergic rhinitis. Allergy Asthma Immunol Res. 2018;10(4):30053.

8 Song Y, Wang M, Xie J, Li W, Zhang X, Wang $\mathrm{T}$, et al. Prevalence of allergic rhinitis among elementary and middle school students in Changsha city and its impact on quality of life. J Laryngol Otol. 2015;129(11):1108-14.

9 Mastrorilli C, Posa D, Cipriani F, Caffarelli C. Asthma and allergic rhinitis in childhood: what's new. Pediatr Allergy Immunol. 2016; 27(8):795-803.

10 Li F, Zhou Y, Li S, Jiang F, Jin X, Yan C, et al. Prevalence and risk factors of childhood allergic diseases in eight metropolitan cities in China: a multicenter study. BMC Public Health. 2011;11:437.
11 Zhang L, Han D, Huang D, Wu Y, Dong Z, Xu $\mathrm{G}$, et al. Prevalence of self-reported allergic rhinitis in eleven major cities in china. Int Arch Allergy Immunol. 2009;149(1):47-57.

12 Ellwood P, Asher MI, Beasley R, Clayton TO, Stewart AW. The international study of asthma and allergies in childhood (ISAAC): phase three rationale and methods. Int $J$ Tuberc Lung Dis. 2005;9(1):10-6.

13 Burney PG, Luczynska C, Chinn S, Jarvis D. The European community respiratory health survey. Eur Respir J. 1994;7(5):954-60.

14 Benavente MG, Truscott RJ. Modification of proteins by 3-hydroxyanthranilic acid: the role of lysine residues. Arch Biochem Biophys. 1991;290(2):451-7.

15 Kong W, Chen J, Wang Y, Xiang J, Zhang X, Wang J, et al. A population-based 5-year follow-up of allergic rhinitis in Chinese children. Am J Rhinol Allergy. 2012 Jul-Aug;26(4): 315-20.

16 Duksal F, Akcay A, Becerir T, Ergin A, Becerir C, Guler N. Rising trend of allergic rhinitis prevalence among Turkish schoolchildren. Int J Pediatr Otorhinolaryngol. 2013;77(9): 1434-9.

17 Sultesz M, Balogh I, Katona G, Mezei G, Hirschberg A, Gálffy G. Trends in prevalence and risk factors of allergic rhinitis symptoms in primary schoolchildren six years apart in Budapest. Allergol Immunopathol. 2017; 45(5):487-95.

18 Patil VK, Kurukulaaratchy RJ, Venter C, Grundy J, Roberts G, Dean T, et al. Changing prevalence of wheeze, rhinitis and allergic sensitisation in late childhood: findings from 2 Isle of Wight birth cohorts 12 years apart. Clin Exp Allergy. 2015;45(9):1430-8.

19 Ha J, Lee SW, Yon DK. Ten-year trends and prevalence of asthma, allergic rhinitis, and atopic dermatitis among the Korean population, 2008-2017. Clin Exp Pediatr. 2020; 63(7):278-83.
20 Galobardes B, Granell R, Sterne J, Hughes R, Mejia-Lancheros C, Davey Smith G, et al. Childhood wheezing, asthma, allergy, atopy, and lung function: different socioeconomic patterns for different phenotypes. Am J Epidemiol. 2015;182(9):763-74.

21 Lee E, Lee SH, Kwon JW, Kim YH, Yoon J, Cho HJ, et al. Persistent asthma phenotype related with late-onset, high atopy, and low socioeconomic status in school-aged Korean children. BMC Pulm Med. 2017;17(1):45.

22 Bilaver LA, Kester KM, Smith BM, Gupta RS. Socioeconomic disparities in the economic impact of childhood food allergy. Pediatrics. 2016;137(5):e20153678.

23 Hwang BF, Jaakkola JJ, Lee YL, Lin YC, Guo YL. Relation between air pollution and allergic rhinitis in Taiwanese schoolchildren. Respir Res. 2006;7:23.

24 Shen J, Ke X, Hong S, Zeng Q, Liang C, Li T, et al. Epidemiological features of allergic rhinitis in four major cities in Western China. J Huazhong Univ Sci Technolog Med Sci. 2011; 31(4):433.

25 Bielory L, Lyons K, Goldberg R. Climate change and allergic disease. Curr Allergy Asthma Rep. 2012;12(6):485-94.

26 Mehanna N, Mohamed N, Wordofa M, Abera D, Mesfin A, Wolde M, et al. Allergy-related disorders (ARDs) among Ethiopian primary school-aged children: prevalence and associated risk factors. PLoS One. 2018;13(9): e0204521.

27 Schuler IC, Montejo JM. Allergic rhinitis in children and adolescents. Pediatr Clin North Am. 2019;66(5):981-93.

28 Deng Q, Lu C, Yu Y, Li Y, Sundell J, Norbäck D. Early life exposure to traffic-related air pollution and allergic rhinitis in preschool children. Respir Med. 2016;121:67-73.

29 Deng Q, Lu C, Ou C, Chen L, Yuan H. Preconceptional, prenatal and postnatal exposure to outdoor and indoor environmental factors on allergic diseases/symptoms in preschool children. Chemosphere. 2016;152: $459-67$.
Prevalence and Risk Factors of Allergic Rhinitis
Int Arch Allergy Immunol 2022;183:34-44 DOI: $10.1159 / 000517948$ 
30 Alm B, Goksör E, Pettersson R, Möllborg P, Erdes L, Loid P, et al. Antibiotics in the first week of life is a risk factor for allergic rhinitis at school age. Pediatr Allergy Immunol. 2014; 25(5):468-72.

31 Alm B, Goksör E, Thengilsdottir H, Pettersson R, Möllborg P, Norvenius G, et al. Early protective and risk factors for allergic rhinitis at age 4(1/2) yr. Pediatr Allergy Immunol. 2011;22(4):398-404.

32 Fuchs O, Genuneit J, Latzin P, Büchele G, Horak E, Loss G, et al. Farming environments and childhood atopy, wheeze, lung function, and exhaled nitric oxide. J Allergy Clin Immunol. 2012;130(2):382-8.e6.
33 Zhang YM, Zhang J, Liu SL, Zhang X, Yang $\mathrm{SN}, \mathrm{Gao}$ J, et al. Prevalence and associated risk factors of allergic rhinitis in preschool children in Beijing. Laryngoscope. 2013;123(1): 28-35.

34 Gough H, Grabenhenrich L, Reich A, Eckers $N$, Nitsche O, Schramm D, et al. Allergic multimorbidity of asthma, rhinitis and eczema over 20 years in the German birth cohort MAS. Pediatr Allergy Immunol. 2015;26(5): 431-7.

35 Chong SN, Chew FT. Epidemiology of allergic rhinitis and associated risk factors in Asia. World Allergy Organ J. 2018;11(1):17.

36 Mazzoni A, D’Elios MM, Mayaregua DR, Spinicci M, Strohmeyer M, Cosmi F, et al. Prevalence of allergy and asthma in a rural community of children and adults in Bolivian Chaco. Immunol Lett. 2019;215:45-7.
37 Igetei JE, El-Faham M, Liddell S, Schramm G Doenhoff MJ. Antigenic cross-reactivity between Schistosoma mansoni and pollen allergens from the birch tree (Betula verrucosa) and Timothy grass (Phleum pratense): involvement of shared glycan epitopes and implications for the hygiene hypothesis. Int $\mathrm{J}$ Parasitol. 2018;48(5):345-57.

38 Wordemann M, Diaz RJ, Heredia LM, Collado Madurga AM, Espinosa AR, Prado RC, et al. Association of atopy, asthma, allergic rhinoconjunctivitis, atopic dermatitis and intestinal helminth infections in Cuban children. Trop Med Int Health. 2008;13(2):180-6. 